\title{
Doctrina Social de la Iglesia
}

\section{$y$ \\ Movimiento Católico Social}

En la epístola de hoy el Apóstol San Pablo dice a los sacerdotes en la persona de su discípulo Timoteo: "To conjuro en la presencia de Dios $Y$. de Cristo Jesús, que ha de juzgar a vivos y muertos, y por su advenimiento y por su reino: predica la palabra, insia a tiempo y a destiempo, reprende, exhorta, increpa con toda loganimidad $y$ no cejando en la enseñanza, Porque vendrá tiempo cuando no soportarán la sana doctrina, antes a medida de sus concupiscencias tomarán para sí maestros con la comezón de oídos que sentirán, y por un lado desviarán sus oídos de la verdad y por otro se volverćn hacia las fábulas. Mas tú anda sobre tí en todo, arrostra los trabajos, haz obra de evangelista, desempeña cumplidamente tu ministerio" (Tim. 4, 1-15).

Este mandato del Apóstol siempre ha sido cumplido en la Iglesia Gatólica y se hace más urgente en nuestros días por la confusión imperante de ideas y actitudes. La presencia actual de la palabra de San Pablo se refleja vivamente en la trase "porque vendrá tiempo cuando no soportarán la sana doctrina, antes a medida de sus concupiscencias tomarón para sí maestros". Cada uno desea acomodar la doctrina evangélica a sus propias ideas intereses, sobre todo en los campos social y político. Debido a esto, deseo recordar $\alpha$ vosotros universitarios, tonto profesores como estudiantes, algunos principios que os servirán de orientación en vuestra vida.

En primer lugar, debe distinguirse entre la doctrina social de la Iglesia y el movimiento católico social: es necesario distinguir los campos y los planos para obtener una acción unificada en profundidad. La palabra "doctrina" tiene sentido diferente para los economistas y para los teólogos. En el lenguaje de los primeros se aplica $\alpha$ un conjunto de principios y conceptos temporales; para los segundos designa un objeto de enseñanza a la vez dogmótico y moral, en el que se encuentran las prescripciones de la moral humana y del derecho natural, el dogma cristiano, los preceptos y los consejos evangélicos. Quiero decir que la doctrina social de la Iglesia no sólo no debe confundirse con el pensamiento de ninguna escuela, cunque sea católica, sino que difiere esencialmente de todo sistema económico, social o político, aunque sea de inspiración crịstiona. 
Situada en el terreno del dogma y de la moral, en el plan espiritual. la doctrina social de la Iglesia deja su amplia libertad a los cristionos en: el orden temporal. Si la moral interviene en toda la conducta humana, ella no se pronuncia sobre el valor propiamente técnico de los medios escogidos para llegar a determinados fines; ella se satisface en aclarar la elección. en particular cuando el empleo de esos medios conduciría a consecuencias inhumanas, pues la Iglesia es guardián de la moral.

La doctrina social de la Iglesia va más allá de las situaciones presentes; dirigida hacia el tuturo, ella propone orientaciones para alcanzar algo mejor que las condiciones actuales. Tales orientaciones obligan a los cristianos, en cuanto nacen de la caridad y de la justicia social, pero dejan un ancho margen de indeterminación al ingenio y a la generosidad de los cristianos, $y$, por consiguiente, de libertad. Cierto que algunos las juzgan muy vagas y diff́cilmente comprenden el respeto de la Iglesia hacia la autonomía de lo temporal, hacia las responsabilidades del Estado y a la libertad de sus hijos. Ejemplo típico ha sido la iniciativa de León XIII y de sus sucesores para que en la remuneración de los asalariados se tuviera en cuenta las cargas familiares, perb sin indicar medios prácticos para su realización. Pareció que se trataba de un pedido ineficaz. Pero tomando en serio las orientaciones de la Iglesia, los cristianos, después de varias tentativas, han descubierto los medios adecuados y el salario familiar se ha introducido en forma permanente, gracias a ello, en numerosas legislaciones.

De ahí que los economistas y políticos deben siempre tener presente que la doctrina social de la Iglesia sólo puede ser interpretada con sanos métodos teológicos y no de economía pura; como tampoco los autores deben confundir su pensamiento propio como el de la Iglesia. Por consiguiente el movimiento católico social, a pesar de su gran autoridad y de su inspiración en los documentos pontificios, no se identitica con la doctrina social de la. Iglesio.

La utilización de los textos pontificios o episcopales debe ser hecha con gran respeto después de un cuidadoso examen. Nada más fácil que recopilar antologías o componer artículos con textos pontificios, separados, yuxtapuestos o reunidos nuevamente, lejos de su contexto literario y de ou contexto histórico; nada más falso $y$ en definitiva menos respetuoso. Resulta que se aproximan textos contradictorios aparentemente, como lo hacen los advesarios. Los Papas y los Obispos hablon "sub specie aeternitatis" pero en circunstancias concretas $\mathrm{y}$ en vista de fines determinados. El pensamiento pontificio no se corta en retazos; es continuidad y progreso desde León XIII hasta Pío XI y Pío XII. Además, no todos los documentos papales ni todos los pasajes de un mismo documento tienen igual valor doctrinario.

El mal uso de los textos pontificios llega al extremo cuando son presentados por los grandes periódicos o por las agencias cablegráficas, que rebajan la doctrina de la Iglesia al servicio de un grupo, de una clase, de un ambiente, perdiendo ella no sólo su eficacia sino su dignidad.

Los miembros de la Iglesia, clérigos y laicos, debemos recalcar que la doctrina social de la Iglesia brota de sus propias fuentes, que son la justicia y la caridad de Cristo y no es producto de una actitud negativacontraria a una determinada situación social o a una ideología errada. Debemos comprender que el Cristianismo toma al hombre íntegro: no puede 
disociarse la vida de piedad de los quehaceres cotidianos, no se es buen cristiano porque se frecuenta los Sacramentos, aun diariamente, y no so cumple con la justicia social. No se puede continuar esa falsa posición de ciertos liberales católicos, que guardan fidelidad a Dios y a la Iglesia en su vida íntima; pero en sus relaciones comerciales prescinden totalmente de sus principios católicos. No puede uno llamarse católico practicamente $\mathrm{y}$, simultáneamente, negar a sus empleados u obreros lo que en justicia les corresponde; o considerar que los principios de justicia social son para las grandes empresas y no para los negocios particulares, o, cínicamente participar en negocios o gestiones francamente inmorales.

Para elaborar una doctrina temporal es necesario que se asuman ciertas opciones determinadas que, para el cristiano, aunque sea libre de aáoptarlas no deben oponerse $\alpha$ las reglas morales. Lo que implica una selección y una adaptación de los medios técnicos a fines concretos y singulares determinados por tales opciones. De suyo, la doctrina social de la Iglesia es universal, valedera para todos los países y para todos los grupos; ella no es ni sindical, ni nacional, ni propiamente política. Tomandó base en ella, los organismos témporales (partidos políticos, sindicatos, etc.), deben usar las libertades que les reconoce la Iglesia para constituir en el plano temporal una doctrina propia, que ellos profesarán y aplicarán bajo su responsabilidad, sin comprometer a la Iglesia, aunque reconozcan su inspiración cristiana.

Una de las razones de la insuficiencia relativa de la acción social cristiana, reside en que no se ha distinguido bien entre la doctrina social de la Iglesia y las doctrinas particulares elaboradas por grupos de inspiración cristiana, que deben ir más lejos por la elección de medios técnicos y de decisiones propiamente temporales. De otra parte, por falta de imaginación Y de audacia, algún grupo se ha reducido a repetir las enseñanzas pontificias sin asumir la responsabilidad de aplicarlas. En cambio, otros por una confusión inconciente, pero peligrosa doctrinaria y apostólicámente, han incluído en la doctrina social de la Iglesia una opinión discutible, $\mathrm{y}$ han pretendido imponerla a todos los cristianos como una consecuencia de su fe, siendo una opinión privada sin otra autoridad que la de sus propios autores.

La doctrina social de la Iglesia no dispensa a los grupos cristionos del necesario esfuerzo intelectual para darse una doctrina propia, adaptada a su situación y a su misión, doctrina sindical o gremial para las organizaciones profesionales, doctrina política para los partidos, etc. Limitase a repetir mecánicamente las enseñanzas de la Iglesia, sería al final de todo una falta de respeto, pues ellas no sólo han sido hechas para ser difundidas, sino sobre todo para ser vividas, es decir aplicadas (1).

Por eso, de manera especial me dirijo a vosotros universitarios que por vuestra cultura estáis llamados a dirigir o a orientar a la sociedad, para que profundiséis vuestros conocimientos religiosos, viváis sinceramente vuestras creencias cristianas, $y$, alumbrados por ellas, lleguéis a ser luz del mundo y sal de la tierra (Mt. 5,13-14), a poner en práctica los principios

(l) Ho utilizado ampliamente la importante Nota Doctrinal del Comité Toológico de Iyon sobre "Les conditions d'efficacité d'une action sociale chrétienne". 
de la doctrina social de la Iglesia y con ella renovar la angustiosa situación en que nos debatimos. Todo ello con firmeza y sencillez, pero con profundidad y sensatez.

La confusión de ideas existente frente a los graves peligros que amenazan al mundo, ha hecho perder en muchas almas cristionas su fe en la Iglesia, y vacilan porque al mirar a su glrededor sólo ven dificultades, considerando entonces que todo va a desaparecer. Mas, debemos tener presente las promeșas del Divino Maestro "que las puertas del infierno no prevalecerán contra ella" (Mt.16,18) y "sabed que estoy con vosotros todos los días hasta la consumación de los siglos". (Mt.28 20). La palabra de Dios no fallara a pesar de las recias tormentas que sacudan a la Iglesia,- puede ser que sean las más terribles que haya tenido que soportar,- recordemos que ya fué anunciado que "sí no se acortaran aquellos días, no se salvará hombre viviente; mas, en atención a los elegidos, serán acortados aquellos días" (Mt. 24,22).

Nuestra fe en el destino de lá Iglesia debe estar basada en las solemnes promesas de Cristo $y$ no debemos amedrentarnos porque puedan desaparecer formas humanas de civilización que tuvieron razgos cristionos, pero que no eran la Iglesia. En esta noche en que participamos todos "de un mismo pan", que es el Cuerpo de Nuestro Señor Jesucristo, se escucha claramente su pregunta ¿Acaso también vosotros queréis. marcharos? $Y$ entonces responderemos junto con Simón Pedro: "Señor, ¿a quién iremos? Tú tienes palabras de vida eterna, y nosotros hemos creído y conocido que Tú eres el Santo de Dios" (Pn.6,67-70).

\section{† JOSE DAMMERT BELLIDO.}

Obispo Auxiliar y Vicario General de la Arquidiócesis de Lima.

Lima, 30 de setiembre de 1960 .

Fiesta de San Jerónimo, Doctor de la Iglesia.

(Sermón pronunciado en la Basílica Metropolitana con motivo de la XVII Comunión Pascual Universitaria. 